\title{
Effect of brachytherapy on NF-кB and VEGF in gastric carcinoma xenografts
}

\author{
WAN-FU ZHANG ${ }^{1}$, WEN-DI JIN ${ }^{1}$, BO LI ${ }^{1}$, MING-CHUN WANG ${ }^{1}$, \\ XIAO-GANG LI ${ }^{1}$, WEN-YUAN MAO ${ }^{1}$ and KAI-YUAN LUO ${ }^{1,2}$ \\ ${ }^{1}$ Department of General Surgery, The Second People's Hospital of Yunnan Province, Kunming, \\ Yunnan 650500; ${ }^{2}$ Department of General Surgery, The Fourth Affiliated Hospital of \\ Kunming Medical University, Kunming, Yunnan 650500, P.R. China
}

Received January 17, 2014; Accepted March 28, 2014

DOI: $10.3892 /$ or.2014.3255

\begin{abstract}
Iodine-125 ( $\left.{ }^{125} \mathrm{I}\right)$ seed irradiation can be used as an important supplementary treatment for unresectable advanced gastric cancer. However, the radiobiological mechanism underlying brachytherapy remains unclear. Therefore, we investigated the influence of continuous and low-energy ${ }^{125} \mathrm{I}$ irradiation on the cell cycle distribution, apoptosis, expression of $\mathrm{NF}-\kappa \mathrm{B}$ and VEGF and tumor growth in a human gastric cancer xenograft model. To create an animal model of gastric cancer, SGC-7901 cells were surgically implanted into mice. The 60 mice bearing SGC-7901 gastric cancer xenografts were randomly separated into 2 groups. Sham seeds $(0 \mathrm{mCi})$ were implanted into the control group $(n=30) ;{ }^{125} \mathrm{I}$ seeds $(0.6 \mathrm{mCi})$ were implanted into the treatment group $(n=30)$. At 28 days after irradiation, apoptosis was detected by flow cytometry. Fluorescence micrograph detected intense VEGF and $\mathrm{NF}-\kappa \mathrm{B}$ immunofluorescence in the tumor samples, and changes in $\mathrm{NF}-\kappa \mathrm{B}$ and VEGF mRNA and protein expression were assessed by real-time PCR and western blot analysis, respectively. The tumor volume and weight were measured 0-28 days after ${ }^{125}$ I seed implantation. ${ }^{125}$ I seed irradiation induced significant apoptosis and $\mathrm{G} 2 / \mathrm{M}$ phase arrest. Reduction in the intensities of VEGF and $\mathrm{NF}-\kappa \mathrm{B}$ immunofluorescence in tumor vessels was observed after treatment. NF- $\kappa \mathrm{B}$ and VEGF mRNA and protein expression levels were substantially lower in the implantation treatment group than in the control group. Consequently, ${ }^{125}$ I seed implantation inhibited cancer growth and reduced cancer volume. The present study revealed that ${ }^{125} \mathrm{I}$ seed irradiation significantly induced apoptosis and cell cycle arrest in the human gastric cancer xenografts. ${ }^{125}$ I-induced changes in $\mathrm{NF}-\kappa \mathrm{B}$ and VEGF expression are suggested as potential mechanisms underlying effective brachytherapy.
\end{abstract}

Correspondence to: Professor Kai-Yuan Luo, Department of General Surgery, The Second People's Hospital of Yunnan Province, Kunming Medical University, Kunming, Yunnan 650500, P.R. China E-mail: luokaiyuanyunnan@163.com

Key words: ${ }^{125} \mathrm{I}$ irradiation, gastric cancer, apoptosis, NF- $\kappa \mathrm{B}$, cell cycle

\section{Introduction}

Gastric cancer is one of the most common types of cancer worldwide, and almost $50 \%$ of gastric cancer-related deaths occur in China (1-3). Surgery offers the only realistic chance of cure; however, many of the patients present with unresectable tumors at the time of diagnosis. Even with resection, more than $50 \%$ of patients relapse and eventually die of their disease $(4,5)$. Therefore, non-surgical methods have attracted increasing attention. In recent years, ${ }^{125} \mathrm{I}$ implantation has been widely used to treat prostate cancer $(6,7)$ and other tumor types $(8,9)$ because of its ability to offer high precision, little trauma, strong lethality and few complications (10-12). Wang and colleagues (13) applied ${ }^{125} \mathrm{I}$ implantation to treat advanced gastric cancer and found significant improvement in clinical symptoms and the quality of life of the patients. Although ${ }^{125} \mathrm{I}$ seed implantations have been successfully applied in the clinic, its biological effects and underlying molecular mechanisms are far from fully understood. Takabayashi and colleagues (14) demonstrated that a continuous low-dose rate of irradiation influenced the proliferation of cells and the apoptosis rate which possibly was the main mechanism of the cell-killing effects in CL187 cells. Ma and colleagues (15) demonstrated that ${ }^{125} \mathrm{I}$ irradiation at $4 \mathrm{~Gy}$ significantly induced cell apoptosis and cell cycle arrest in gastric cancer cells.

The best known and the most efficient growth factors involved in tumor angiogenesis are vascular endothelial growth factor (VEGF) and nuclear factor- $\kappa \mathrm{B}(\mathrm{NF}-\kappa \mathrm{B})$. Their activation has been connected with multiple aspects of oncogenesis, such as apoptotic resistance, transformation, growth, metastasis and angiogenesis. Li et al (16) found that inhibition of the NF- $\mathrm{NB}$ p 65 signaling pathway may be considered as a potential strategy for treating gastric cancer. Various studies examined the relationship between VEGF expression and the clinical outcome of patients with gastric cancer and found that VEGF expression in gastric cancer tissue is associated with poor survival (17). Thus, irradiation-induced apoptosis, inhibition of cell proliferation and VEGF and $\mathrm{NF}-\kappa \mathrm{B}$ signal transduction may be key mechanisms underlying the therapeutic effect of low energy ${ }^{125}$ I seed implantation. In the present study, we investigated the role of VEGF and NF- $\kappa \mathrm{B}$ in 
the process of ${ }^{125} \mathrm{I}$ brachytherapy and ${ }^{125} \mathrm{I}$-induced cell apoptosis and cell cycle changes in a xenograft model.

\section{Materials and methods}

Animal model. Human SGC-7901 cells (3×10\%/mouse) were subcutaneously injected into the right dorsal flank of BALB/ c-nu/nu nude mice. After 1-2 weeks of implantation with tumor cells, when tumors reached $20-30 \mathrm{~mm}^{3}$, the animals were randomized into control and treatment groups (30 animals per group). The ${ }^{125} \mathrm{I}$ seeds $(0.6 \mathrm{mCi})$ were injected into the mice in the treatment group through an 18-gauge needle, while ghost seed were injected into the mice in the control group. The tumor size was measured using calipers, and the tumor volume $(\mathrm{V})$ was estimated by the following formula: (V) $\left(\mathrm{mm}^{3}\right)=(\mathrm{L} \mathrm{xW}) \times 1 / 2$, where $\mathrm{L}$ is the length and $\mathrm{W}$ is the width of the tumor.

Tumor volumes and body weights were monitored every 3 days over the course of treatment. The tumor weight was measured when the mice were sacrificed. Mice were sacrificed after 28 days of treatments, and tumors were removed and fixed in $10 \%$ neutral buffered formalin for histologic and immunohistochemical analyses. All animal procedures were carried out with the approval of the Animal Ethics Committee of Kunming Medical College.

Histological analysis of tumors and immunofluorescence examination of VEGF and $N F-\kappa B$. Tumors were embedded in paraffin, sectioned $(5 \mu \mathrm{m})$ and stained with hematoxylin and eosin (H\&E) (Sigma-Aldrich, St. Louis, MO, USA). For the immunofluorescence staining of NF- $\kappa \mathrm{B}$ and VEGF, the frozen sections were maintained at room temperature for $30 \mathrm{~min}$, incubated in distilled water for $5 \mathrm{~min}$ and in PBS for $5 \mathrm{~min}$ and permeabilized in $1 \mathrm{~g} / 1$ Triton X-100 for $10 \mathrm{~min}$. The sections were subsequently washed with PBS (5 min $x$ 3), blocked with $100 \mathrm{ml}$ sheep serum (Sigma) at $37^{\circ} \mathrm{C}$ for $20 \mathrm{~min}$ and incubated in the primary antibodies: rat anti-mouse NF- $\kappa$ B (BioLegend, San Diego, CA, USA) and rabbit anti-human VEGF polyclonal antibody (LabVision Corp., Fremont, CA, USA) at $4^{\circ} \mathrm{C}$ overnight and washed with PBS (5 min $x$ 3). Incubation in the secondary antibody (goat anti-rat IgG-conjugated TRITC or sheep anti-rabbit IgG-conjugated FITC; Sigma) was carried out for $1 \mathrm{~h}$ at $37^{\circ} \mathrm{C}$. Sections were washed with PBS (10 min x 3 ) and then examined under a TCS SP2 laser confocal microscope. For each group, several field images of VEGF and NF- $\kappa \mathrm{B}$ in each tumor tissue section were captured under a confocal microscope. The fluorescence intensity of each section in the confocal fluorescence images was measured using the Leica confocal analysis system. The mean fluorescence intensity in each section was then calculated.

Cell cycle distribution analysis. Cells in the mono-dispersed suspension were fixed with ethanol, followed by propidium iodide staining (PI; Sigma) and analyzed using the FACSCalibur flow cytometer (BD Biosciences, San Jose, CA, USA). Percentages of cells resting in the G1, S and G2/M phases were determined with CellQuest software (BD Biosciences) and ModFit LT software (Verity Software House, Topsham, ME, USA).
Annexin VIPI assay of ${ }^{125}$ I-induced apoptosis. The cells were stained with Annexin V-FITC and PI, and evaluated for apoptosis by flow cytometry according to the manufacturer's protocol (BD Pharmingen, San Diego, CA, USA). Both early (Annexin V-positive, PI-negative) and late (Annexin V-positive, PI-positive) apoptotic cells were counted as apoptotic cells.

Total RNA preparation. The samples were ground by using liquid nitrogen. Total RNA was extracted from lung tissues by using an animal tissue RNA purification kit (Norgen Biotek Corp., Thorold, ON, Canada) as recommended by the manufacturer. RNA samples were measured by using a bioanalyzer to determine RNA integrity number.

Quantitative real-time PCR. The approximate length of miRNA at 21-23 nt resulted in difficulties in conventional PCR test. We used TaqMan ${ }^{\circledR}$ MicroRNA Assays (Applied Biosystems, Foster City, CA, USA) to examine miRNA differential expression profiling in PTC as recommended by the manufacturer. Sample RNA (10 ng) was reversely transcribed into cDNA by using specific stem-loop primers and TaqMan ${ }^{\circledR}$ MicroRNA reverse transcription kit. With cDNA as the template, TaqMan MicroRNA Assay and the TaqMan ${ }^{\circledR}$ Universal PCR Master Mix were used for the serial real-time PCR. RNU48 was used as an internal control to minimize the variation among reverse transcription, PCR and samples. The data were collected, analyzed, and normalized by using the Applied Biosystems analysis software to determine the differential expression profiles of miRNAs. All of the experiments were performed in triplicate. Expression levels were calculated by using the relative quantification method $(\Delta \Delta \mathrm{CT})$ in the ABI PRISM 7500 Sequence Detection system (Applied Biosystems), according to the manufacturer's protocol.

Western blot analysis. Proteins were resolved on $12 \%$ polyacrylamide gels, transferred to a nitrocellulose membrane (Bio-Rad Laboratories, Hercules, CA, USA) and blocked with $5 \%$ non-fat dairy milk in Tris-buffered saline $(20 \mathrm{mM}$ Tris, $150 \mathrm{mM} \mathrm{NaCl}, \mathrm{pH} 7.4$ ) with $0.1 \%$ Tween-20.

Statistical analysis. The results of the animal experiments and real-time PCR were analyzed using SPSS 13.0 software. (SPSS Inc., Chicago, IL, USA). All data were plotted as mean \pm standard deviation. Student's t-test was used to compare values between two independent groups. Differences were considered to be significant at $\mathrm{P}<0.05$.

\section{Results}

Inhibitory effect of ${ }^{125}$ I seed irradiation on the growth of gastric cancer. The effectiveness of ${ }^{125} \mathrm{I}$ seed irradiation to inhibit the growth of implanted SGC-7901 tumors was examined in a nude mouse model. There were no significant changes in the tumor volumes for the first 10 days of the ${ }^{125} \mathrm{I}$ seed treatment. However, after 13 days, the ${ }^{125}$ I-irradiated tumors were much smaller, and a significant difference in tumor volume was observed over time between the control and ${ }^{125}$ I treatment group (Fig. 1A). On day 28, the mice were sacrificed and tumor weights were measured. Statistical difference in the tumor weight was observed between the control 

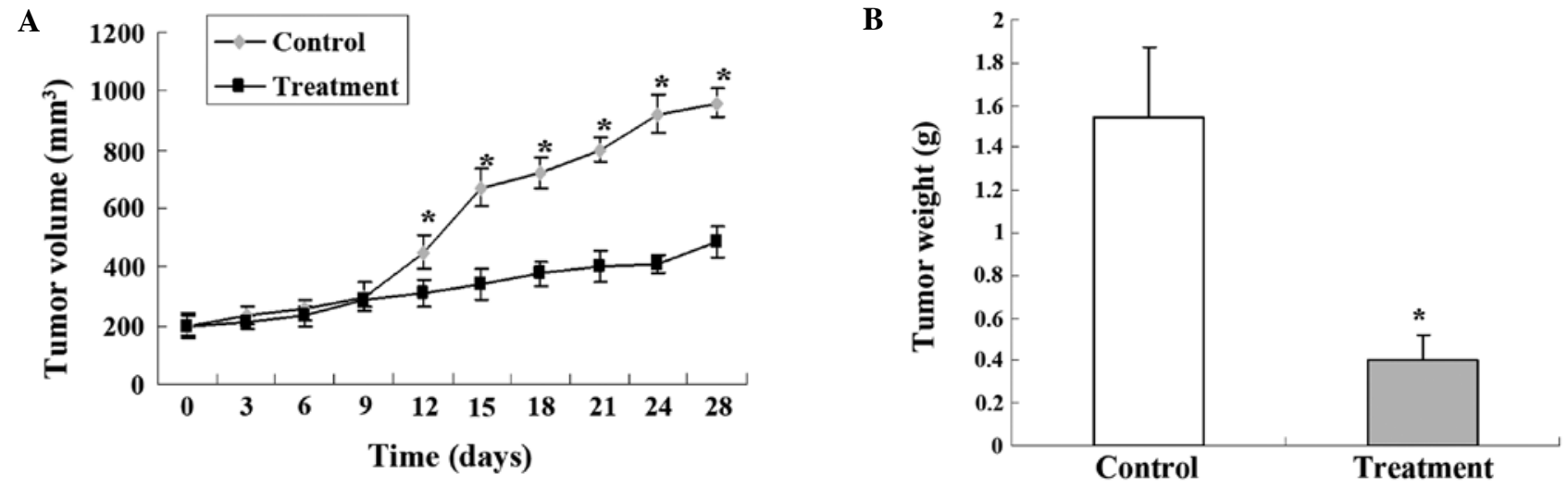

Figure 1. Effect of ${ }^{125} \mathrm{I}$ on the gastric cancer xenograft model. Data represent means $\pm \mathrm{SD}$ ( $\mathrm{n}=30$ /group). (A) The treatment group exhibited a decreased tumor weight compared to the control group ("P<0.05). (B) The treatment group had a smaller tumor volume compared to the control group from day 13 ("P $<0.05$ ).

A

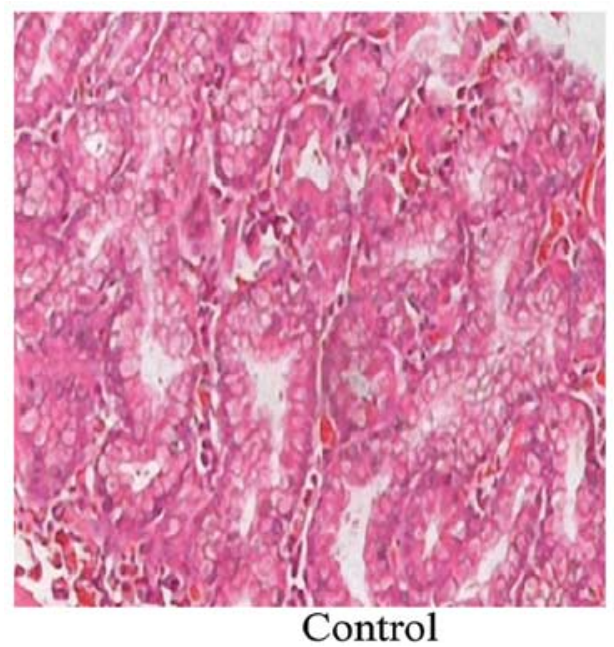

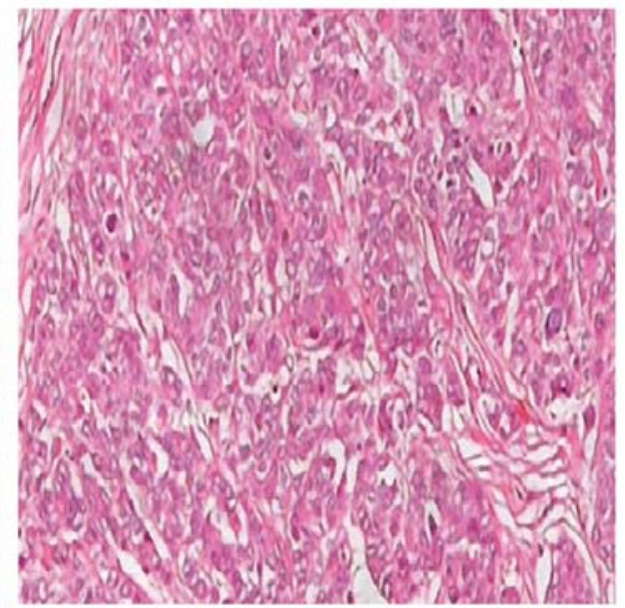

Treatment

Figure 2. Evaluation of the antitumor efficacy of ${ }^{125} \mathrm{I}$ on xenograft tumors. Images of representative H\&E staining of (A) control and (B) treated tumor tissue sections.

and treatment group (Fig. 1B). All these data clearly indicated that ${ }^{125}$ I seed implantation effectively inhibited tumor growth. In addition, the body weights of the mice were not affected by the ${ }^{125}$ I irradiation and no obvious radiation-induced damage was observed in the vital organs of the mice (data not shown), indicating the safety of the ${ }^{125}$ I seed treatment.

Effect of ${ }^{125}$ I seed irradiation on morphology of gastric cancer tumors. To investigate the effect of the ${ }^{125} \mathrm{I}$ irradiation on the histology of the SGC-7901 xenografts, tumor sections were obtained from mice in the control and the ${ }^{125}$ I treatment group and were stained using H\&E. As shown in Fig. 2, the histological appearance of the tumors in the control group was quite different from that in the ${ }^{125} I$ treatment group. In the control group, the cancer cells were densely arranged with large darkly stained nuclei and obvious karyokinesis. In the treatment group, large necrotic regions were observed around the ${ }^{125}$ I seed. The cancer cells adjacent to the necrotic region were loosely arranged with condensed nuclei and reduced eosinophilic cytoplasm. These results indicated that ${ }^{125} \mathrm{I}$ seed implantation caused growth inhibition of cancer cells in the SGC-7901 xenografts.
Effect of ${ }^{125}$ I seed irradiation on cell apoptosis and cell cycle distribution in the gastric cancer tumors. To quantitatively compare the cell cycle and apoptotic index of tumors treated with ${ }^{125}$ I seed irradiation, FACS was performed. The cell cycle was blocked in the G2/M phase in the tumors in the ${ }^{125} \mathrm{I}$ treatment group when compared to the tumors in the control group (Fig. 3A). The percentage of apoptotic cells was significantly increased in the ${ }^{125} \mathrm{I}$ treatment group when compared to the percentage of apoptotic cells in the control group (Fig. 3B).

Effect of ${ }^{125} I$ on VEGF and NF- $\kappa B$ immunofluorescence staining. Expression of VEGF and NF- $\mathrm{kB}$ was confirmed by the presence of fluorescence-stained cytoplasm in the cells. Strong immunoreactivity to VEGF and NF- $\kappa B$ was found in the SGC-7901 tumor xenografts of the control group (Fig. 4A-a and -b). Weaker fluorescence intensity expression was observed in the SGC-7901 tumors of the group treated with ${ }^{125}$ ( Fig. 4A-c and -d). The fluorescence intensity levels of VEGF and NF- $\mathrm{KB}$ in the tumor cells were significantly lower in the radiation-treated group than levels in the control group (Fig. 4B; P<0.01). 


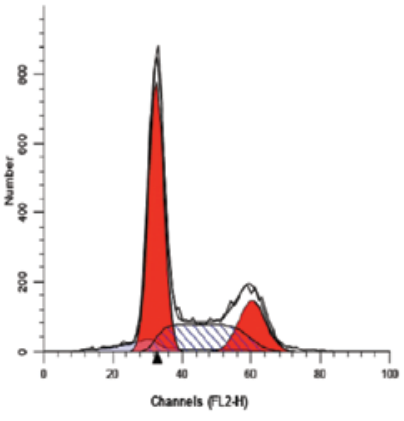

Control

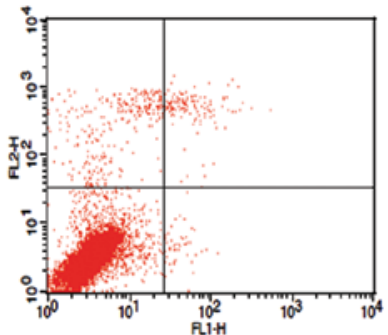

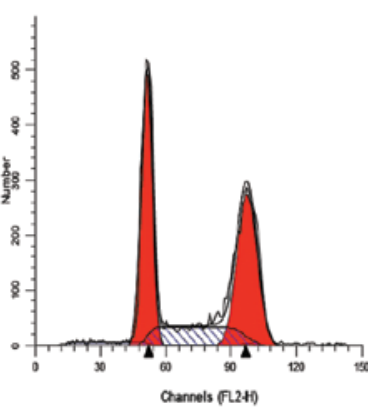

Treatment

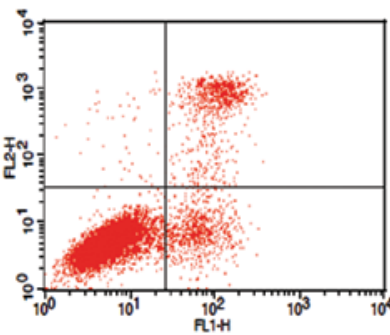

A

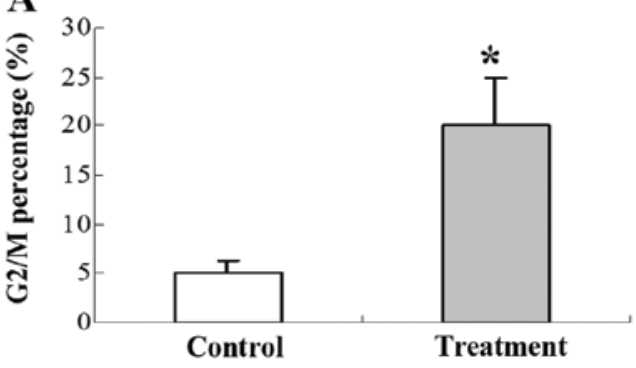

B

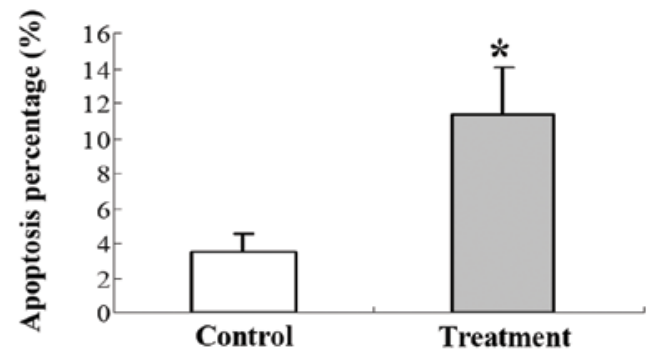

Figure 3. Summary of G2/M phase distribution and percentage of apoptosis. The treatment group exhibited significant increases in (A) G2/M cell cycle distribution and (B) the percentage of cell apoptosis. ${ }^{*} \mathrm{P}<0.05$ for the comparison between control and ${ }^{125} \mathrm{I}$ treatment.
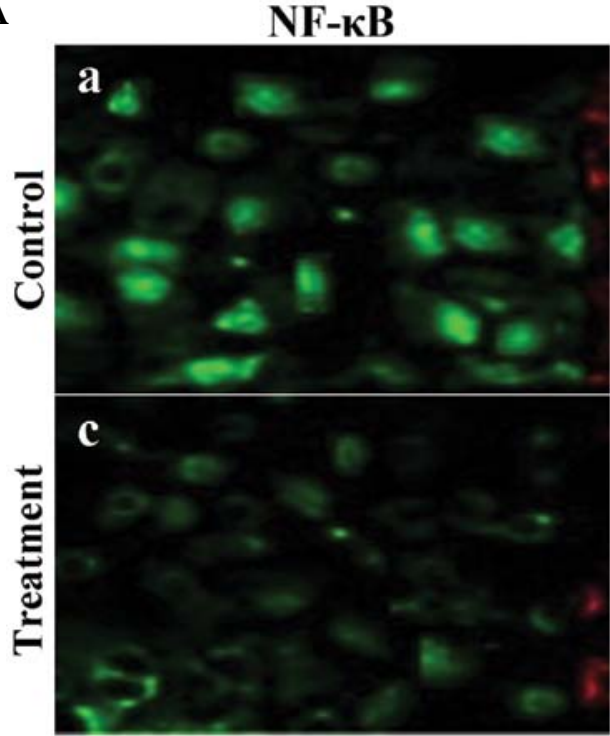

VEGF

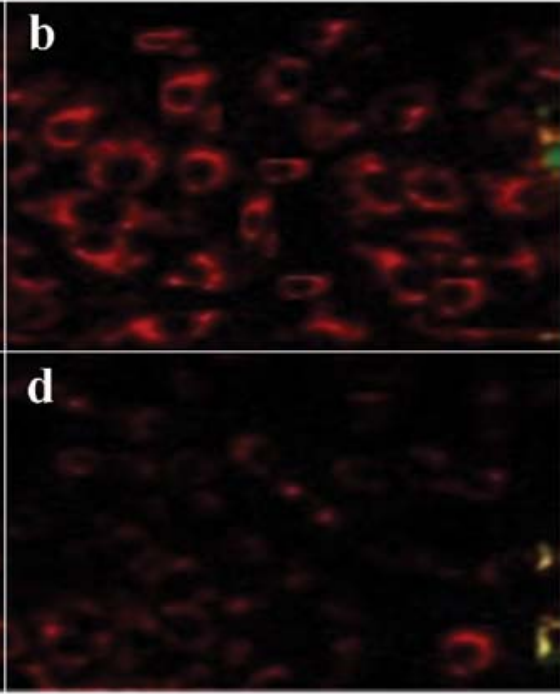

B

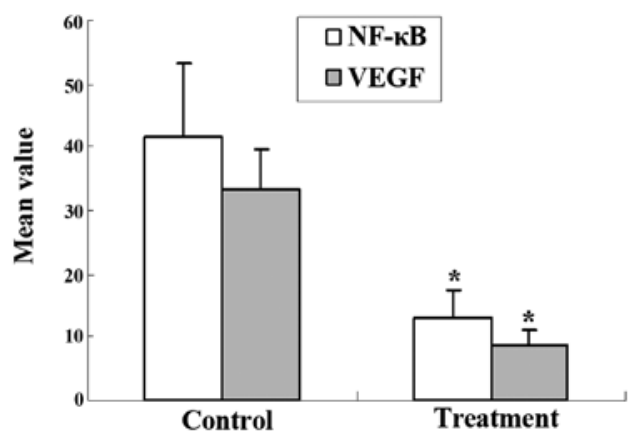

Effect of ${ }^{125} I$ on the expression of VEGF and NF- $\kappa B$ mRNA and protein in the tumor tissues. To further analyze the effect of ${ }^{125} \mathrm{I}$ radiation on VEGF and NF- $\mathrm{BB}$ expression in tumors, we assessed VEGF and NF- $\mathrm{kB}$ expression in SGC-7901 cells
Figure 4. Immunofluorescence double staining and confocal laser scanning analysis. Results showed that NF- $\kappa \mathrm{B}$ and VEGF were expressed in the tissues. (A) NF- $\mathrm{KB}$ (a) and VEGF (b) staining intensities in the control group was higher than these values in the treatment group (c and d). (B) Bars in the histogram represent the mean values of immunofluorescence intensities of VEGF and NF- $\mathrm{B}$ in the two groups, ${ }^{*} \mathrm{P}<0.01$.

in vitro using western blotting and fluorescent quantitative RT-PCR. Western blot analysis revealed that the expression of VEGF and NF- $\mathrm{KB}$ protein was decreased in the treatment group (Fig. 5B). Furthermore, VEGF and NF- $\kappa \mathrm{B}$ mRNA 

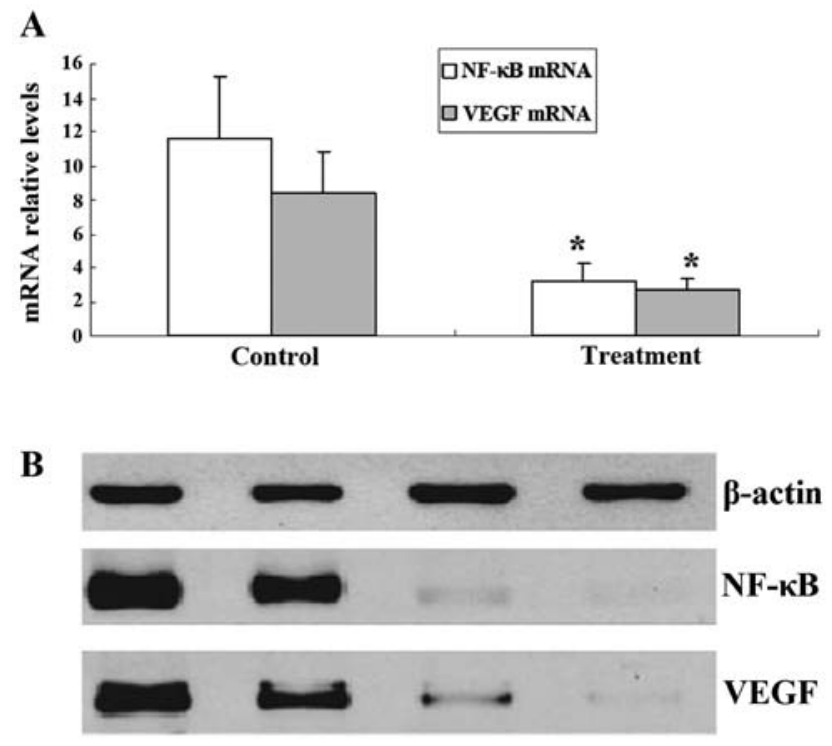

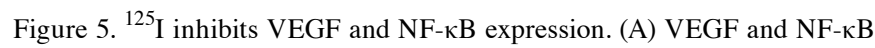
mRNA and (B) protein levels were significantly decreased in the ${ }^{125}$ I seed implantation xenograft tissue samples.

expression was in agreement with the protein expression results as mRNA data also revealed a significant difference between the control and the treatment group (Fig. 5A).

\section{Discussion}

Several recent studies suggest that apoptosis and cell cycle arrest may have important roles in the therapeutic effects of continuous low-energy ${ }^{125} \mathrm{I}$ irradiation $(14,15,18)$. In addition, the VEGF and NF- $\mathrm{NB}$ signaling pathway may be involved in the gastric cancer oncogenic signaling pathway (19). However, comprehensive knowledge on this topic, particularly at the molecular level, is still lacking. In the present study, analysis of cell apoptosis and the cell cycle, as well as VEGF and NF- $\kappa \mathrm{B}$ expression analysis of human gastric cancer xenografts exposed to ${ }^{125}$ I seed irradiation were performed to gain insight into the mechanisms underlying the biological effects of ${ }^{125} \mathrm{I}$ irradiation.

SGC-7901 gastric cancer cells were implanted into nude mice to create a xenograft animal model. The growth curves of tumors indicated that irradiation induced significant tumor growth inhibition. By observing H\&E-stained slides, a large number of apoptotic cells was observed in the gastric cancer tumors receiving ${ }^{125}$ I seed implantation. These results showed that ${ }^{125} \mathrm{I}$ suppressed the growth of the gastric cancer xenografts in the nude mice, while inhibiting cell proliferation and inducing apoptosis. Our results further demonstrated that continuous low-dose-rate irradiation by ${ }^{125} \mathrm{I}$ seeds reduced cell viability and induced cell apoptosis, and led to the accumulation of cells in the G2/M phase. These data suggest that the cell cycle was blocked in the $\mathrm{G} 2$ phase after radiation. Cells in the G2 phase are more sensitive to radiation (20), and therefore, more tumor cells were eliminated.

Our VEGF and NF- $\kappa \mathrm{B}$ analyses in the tumor cells indicated decreased fluorescence intensity implying reduced mRNA and protein levels in the treatment cells as compared with the control cells. A previous study demonstrated a correlative expression relationship between VEGF and NF- $\mathrm{KB}$ in $80 \mathrm{ACC}$ clinical samples (21). Evidence also indicates that overexpression of $\mathrm{NF}-\kappa \mathrm{B}$ is the key component of the angiogenic cascade, which contributes to VEGF-induced angiogenesis through upregulation of VEGF mRNA expression in many tumor types $(22,23)$.

$\mathrm{NF}-\kappa \mathrm{B}$ is a family of homodimeric or heterodimeric transcription factors formed by proteins of the Rel family. Recently, it has been suggested that NF- $\kappa \mathrm{B}$ plays an important role in carcinogenesis (24). There is evidence that $N F-\kappa B$ is constitutively activated in gastric cancer tissues, with higher levels in gastric carcinoma cells in comparison to normal adjacent epithelial cells (25). In gastric cancer, abnormal NF- $\kappa \mathrm{B}$ activation has been shown to lead to enhanced proliferation, evasion of apoptosis, genomic instability, increased rate of glycolysis and drug resistance (26-28).

VEGF, a dimeric 42-kDa protein, is a multifunctional cytokine that plays a key role in both physiological and pathological angiogenesis. It was identified in tumor cells of gastric cancer more than 10 years ago (29). Several groups of investigators have reported a correlation between VEGF expression and microvessel density in human gastric cancer (30). Our data together with previous research evidence suggest that $\mathrm{NF}-\kappa \mathrm{B}$ and VEGF play an important role in the therapeutic effects of continuous low-energy ${ }^{125} \mathrm{I}$ irradiation and are involved in the mechanism of the ${ }^{125}$ I seed implantation therapy process.

In conclusion, the present study demonstrated that human gastric tumor cells following ${ }^{125} \mathrm{I}$ brachytherapy showed induced cell apoptosis and cell cycle arrest in the G2/M phase in a xenograft model. Furthermore, suppression of $\mathrm{NF}-\kappa \mathrm{B}$ activity through significantly decreased VEGF expression facilitates the ${ }^{125}$ I clinical effect on gastric tumors. The results indicate that brachytherapy is a useful strategy in gastric tumor therapy. Further study by us will investigate the function of $\mathrm{NF}-\kappa \mathrm{B}$ and VEGF signaling in angiogenesis and metastasis of gastric tumor cells.

\section{Acknowledgements}

The present study was supported by a grant from Yunnan Province (no. 2013FZ189).

\section{References}

1. Power DG, Kelsen DP and Shah MA: Advanced gastric cancerslow but steady progress. Cancer Treat Rev 36: 384-392, 2010.

2. Shen L, Shan YS, Hu HM, Price TJ, Sirohi B, Yeh KH, Yang YH, et al: Management of gastric cancer in Asia: resource-stratified guidelines. Lancet Oncol 14: e535-e547, 2013.

3. Ferlay J, Shin HR, Bray F, Forman D, Mathers C and Parkin DM: Estimates of worldwide burden of cancer in 2008: GLOBOCAN 2008. Int J Cancer 127: 2893-2917, 2010.

4. Joensuu H, Vehtari A, Riihimäki J, Nishida T, Steigen SE, Brabec P, Plank L, et al: Risk of recurrence of gastrointestinal stromal tumour after surgery: an analysis of pooled populationbased cohorts. Lancet Oncol 13: 265-274, 2012.

5. Marrelli D, De Stefano A, de Manzoni G, Morgagni P, Di Leo A and Roviello F: Prediction of recurrence after radical surgery for gastric cancer: a scoring system obtained from a prospective multicenter study. Ann Surg 241: 247-255, 2005.

6. Merrick GS, Wallner KE and Butler WM: Permanent interstitial brachytherapy for the management of carcinoma of the prostate gland. J Urol 169: 1643-1652, 2003.

7. Roeloffzen EM, Monninkhof EM, Battermann JJ, et al: Acute urinary retention after I-125 prostate brachytherapy in relation to dose in different regions of the prostate. Int J Radiat Oncol Biol Phys 80: 76-84, 2011. 
8. Lee W, Daly BD, DiPetrillo TA, et al: Limited resection for non-small cell lung cancer: observed local control with implantation of I-125 brachytherapy seeds. Ann Thorac Surg 75: 237-243, 2003

9. Zhuang HQ, Wang JJ, Liao AY, Wang JD and Zhao Y: The biological effect of ${ }^{125} \mathrm{I}$ seed continuous low dose rate irradiation in CL187 cells. J Exp Clin Cancer Res 28: 12, 2009.

10. Ma JX, Jin ZD, Si PR, Liu Y, Lu Z, Wu HY, Pan X, et al: Continuous and low-energy ${ }^{125}$ I seed irradiation changes DNA methyltransferases expression patterns and inhibits pancreatic cancer tumor growth. J Exp Clin Cancer Res 30: 35, 2011.

11. Wang JJ, Yuan HS, Li JN, Jiang WJ, Jiang YL and Tian SQ Interstitial permanent implantation of ${ }^{125}$ I seeds as salvage therapy for re-recurrent rectal carcinoma. Int J Colorectal Dis 24: 391-399, 2009

12. Shi L, Wu C, Wu J, Zhou W, Ji M, Zhang H, et al: Computed tomography-guided permanent brachytherapy for localregional recurrent gastric cancer. Radiat Oncol 7: 114, 2012.

13. Wang J, Sui A, Jia Y, Xu B, Wei L, Chen J and Shen W: Treatment of unresectable advanced gastric cancer using iodine-125 brachytherapy. Chin J Clin Oncol 3: 212-215, 2006.

14. Takabayashi K, Kashiwagi K, Kawata T, Sato T, Matsuoka K, Hisamatsu T, Takaishi $\mathrm{H}$, et al: Continuous low-dose irradiation by I-125 seeds induces apoptosis of gastric cancer cells regardless of histological origin. Cancer Biol Ther 5: 81-88, 2014.

15. Ma ZH, Yang Y, Zou L and Luo KY: 125I seed irradiation induces up-regulation of the genes associated with apoptosis and cell cycle arrest and inhibits growth of gastric cancer xenografts J Exp Clin Cancer Res 31: 61, 2012.

16. Li ZM, Pu YW and Zhu BS: Blockade of NF- $\kappa B$ nuclear translocation results in the inhibition of the invasiveness of human gastric cancer cells. Oncol Lett 6: 432-436, 2013.

17. Cao W, Fan R, Yang W and Wu Y: VEGF-C expression is associated with the poor survival in gastric cancer tissue. Tumour Biol: Dec 5, 2013 (Epub ahead of print).

18. Yang Z, Jin C, Chen T, Sun H, Yang D, Huang Y, Zhang J, et al: Changes in cell cycle, apoptosis and necrosis following the establishment of a ${ }^{125} \mathrm{I}$ brachytherapy model in the spinal cord in Banna mini-pigs. Oncol Lett 3: 315-320, 2012.

19. Santos-Silva F: Oncogenic signaling in gastric carcinoma. In: Gastric Carcinoma - Molecular Aspects and Current Advances. Lotfy M (ed). InTech, Rijeka, Croatia, 2011. doi:10.5772/21729. Available from: http://www.intechopen.com/books/gastriccarcinoma molecular aspects and current advances/oncogenic signaling in gastric carcinoma.
20. Yan Y, Greer PM, Cao PT, Kolb RH and Cowan KH: RAC1 GTPase plays an important role in $\gamma$-irradiation induced $\mathrm{G}_{2} / \mathrm{M}$ checkpoint activation. Breast Cancer Res 14: R60, 2012.

21. Zhang J, Peng B and Chen X: Expressions of nuclear factor $\kappa B$, inducible nitric oxide synthase and vascular endothelial growth factor in adenoid cystic carcinoma of salivary glands: correlations with the angiogenesis and clinical outcome. Clin Cancer Res 11: 7334-7343, 2005.

22. Zhang $\mathrm{J}$ and Peng $\mathrm{B}$ : In vitro angiogenesis and expression of nuclear factor $\mathrm{\kappa B}$ and VEGF in high and low metastasis cell lines of salivary gland adenoid cystic carcinoma. BMC Cancer 7: 95 , 2007.

23. Fujioka S, Sclabas GM, Schmidt C, Frederick WA, Dong QG, Abbruzzese JL, et al: Function of nuclear factor $\kappa \mathrm{B}$ in pancreatic cancer metastasis. Clin Cancer Res 9: 346-354, 2003.

24. Du ZX, Zhang HY, Gao DX, Wang HQ, Li YJ and Liu GL: Significance of VEGF and NF- $\mathrm{KB}$ expression in thyroid carcinoma. Chin J Clin Oncol 3: 166-171, 2006.

25. Sasaki N, Morisaki T, Hashizume K, Yao T, Tsuneyoshi M, Noshiro $\mathrm{H}$, et al: Nuclear factor $\kappa \mathrm{B}$ p65 (RelA) transcription factor is constitutively activated in human gastric carcinoma tissue. Clin Cancer Res 7: 4136-4142, 2001.

26. Tsuboi K, Matsuo Y, Shamoto T, Shibata T, Koide S, Morimoto M, et al: Zerumbone inhibits tumor angiogenesis via NF- $\kappa \mathrm{B}$ in gastric cancer. Oncol Rep 31: 57-64, 2014.

27. Kang MJ, Ryu BK, Lee MG, Han J, Lee JH, Ha TK, Byun DS, et al: NF- $\mathrm{KB}$ activates transcription of the RNA-binding factor $\mathrm{HuR}$, via PI3K-AKT signaling, to promote gastric tumorigenesis. Gastroenterology 135: e2031-e2033, 2008

28. Liu X, Wang X, Zhang J, Lam EK, Shin VY, Cheng AS, et al: Warburg effect revisited: an epigenetic link between glycolysis and gastric carcinogenesis. Oncogene 29: 442-450, 2010.

29. Raica M, Mogoantă L, Cîmpean AM, Alexa A, Ioanovici S, Mărgăritescu C, et al: Immunohistochemical expression of vascular endothelial growth factor (VEGF) in intestinal type gastric carcinoma. Rom J Morphol Embryol 49: 37-42, 2008.

30. Kitadai Y: Angiogenesis and lymphangiogenesis of gastric cancer. J Oncol 2010: 468725, 2010. doi:10.1155/2010/468725. 